\title{
High-Temperature Confocal Laser Scanning Microscopy Studies of Ferrite Formation in Inclusion-Engineered Steels: A Review
}

\author{
WANGZHONG MU $\oplus,{ }^{1,3}$ PETER HEDSTRÖM, ${ }^{1}$ HIROYUKI SHIBATA, ${ }^{2}$ \\ PÄR G. JÖNSSON, ${ }^{1}$ and KEIJI NAKAJIMA ${ }^{1}$ \\ 1.-Department of Materials Science and Engineering, KTH Royal Institute of Technology, \\ Brinellvägen 23, 10044 Stockholm, Sweden. 2.-Institute of Multidisciplinary Research for \\ Advanced Materials, Tohoku University, 2-1-1 Katahira, Aoba-ku, Sendai, Miyagi 980-8577, \\ Japan. 3.—e-mail: wangzhongmu6699@gmail.com
}

\begin{abstract}
The concepts of oxide metallurgy and inclusion engineering can be utilized to improve the properties of low-alloy steels. These concepts aim at controlling the formation of intragranular ferrite (IGF), often a desirable microstructure providing good mechanical properties without the need for expensive alloying elements. IGF formation is stimulated to occur at non-metallic inclusions and form an arrangement of fine, interlocking ferrite grains. A method that has contributed significantly to investigations in this field lately is high-temperature confocal laser scanning microscopy (HT-CLSM). HT-CLSM is suited for in situ studies of inclusion behavior in liquid steel and phase transformations in solidstate steel, where in particular, displacive phase transformations can be studied, since they provide sufficient topographic contrast. The purpose of the present report is to provide a brief review of the state of the art of HT-CLSM and its application for in situ observations of ferrite formation in inclusion-engineered steels. The scientific literature in this field is surveyed and supplemented by new work to reveal the capability of HT-CLSM as well as to discuss the effect of factors such as cooling rate and parent grain size on IGF formation and growth kinetics. The report concludes with an outlook on the opportunities and challenges of HT-CLSM for applications in oxide metallurgy.
\end{abstract}

\section{INTRODUCTION}

Clean steels are in increasing demand to optimize mechanical properties such as fatigue properties, and the vision of process metallurgists is to produce steels without inclusions. However, there is limited knowledge regarding how to remove and modify inclusions during secondary refining in steelmaking, and formation of inclusions is inevitable using current industrial steelmaking practice. ${ }^{1-4}$ Accepting this, researchers have also tried to benefit from inclusions; For example, it has been shown that certain non-metallic inclusions, such as $\mathrm{Ti}$ oxide, $\mathrm{TiN}$, and $\mathrm{V}(\mathrm{C}, \mathrm{N})$, can serve as effective nucleation sites for formation of intragranular ferrite (IGF). The preferential formation of IGF, instead of grain boundary ferrite (GBF), improves the toughness of steel. This concept of utilizing inclusions within the physical metallurgy discipline is known as oxide metallurgy, introduced by Takamura and cowork$\mathrm{ers}^{5-8}$ in 1990. Their research described utilization of fine oxide inclusions to improve the quality of the final steel product. Another related concept is known as inclusion engineering, emphasizing control of the amount, morphology, size distribution, and chemical composition of the inclusions formed in liquid steel during the refining process. ${ }^{9}$ In the present report, we use the concept of oxide metallurgy, since the emphasis here is on the microstructural aspects, as opposed to the inclusion characteristics. Oxide metallurgy is a relatively new concept, ${ }^{10}$ but utilization of IGF microstructures can be dated back to six decades ago. ${ }^{11}$ Hence, oxide metallurgy mainly stresses the correlation between inclusions and microstructure and requires consideration of both process and physical 
metallurgy. Oxide metallurgy has so far primarily been used to improve the toughness and strength of the coarse-grained heat-affected zone (CGHAZ) in weldments. ${ }^{12}$ Recently, reports on how to improve the properties of various steel grades, including high-strength low-alloy (HSLA) steels, line pipe steels, and off-shore steels, ${ }^{13,14}$ have also been presented.

One methodology that has become valuable for investigation of austenite decomposition in oxide metallurgy is high-temperature confocal laser scanning microscopy (HT-CLSM). It provides a robust tool for in situ real-time studies of phase transformations during heat treatment. The pioneering work on application of HT-CLSM dates back to the work of Emi and coworkers. ${ }^{15-19}$ In addition to investigations on austenite decomposition in steels, HT-CLSM has also been applied to study, for example, crystal growth during solidification of a steel melt, ${ }^{15}$ inclusion agglomeration at the liquid steel-Ar gas interface, ${ }^{17,18,20,21}$ and engulfment and pushing of inclusions at the melt-solid interface of steel. ${ }^{19}$

The aim of the present report is to survey the application of the HT-CLSM technique for investigation of IGF formation in steels utilizing oxide metallurgy. This literature survey is supplemented by new HT-CLSM work to investigate the austenite decomposition in a steel with $\mathrm{TiO}_{2}$ addition. The report starts with an introduction to HT-CLSM and the state of the art of HT-CLSM instrumentation. Thereafter, we provide a literature review of HTCLSM studies on austenite decomposition within oxide metallurgy. Subsequently, we present a more in-depth summary of selected insights gained from HT-CLSM that have contributed to understanding of oxide metallurgy in steels. We conclude this report with a discussion about the opportunities and challenges in applying HT-CLSM for studying austenite decomposition in steels and relate this to opportunities in neighboring fields.

\section{HIGH-TEMPERATURE CONFOCAL LASER SCANNING MICROSCOPY}

\section{Working Principle and Instrumentation}

The design of a modern HT-CLSM microscope is detailed in Fig. 1. The sample is positioned in a crucible, which is placed inside the furnace chamber on a Pt sample holder. A thermocouple wire is incorporated into the $\mathrm{Pt}$ sample holder to measure the temperature from the bottom of the crucible. A halogen infrared (IR) heating lamp is situated underneath the sample holder to heat the specimen, which is placed at the focal point of the IR beam that is reflected by the gold coating covering the inside of the ellipsoidal chamber. In the first HT-CLSM study reported by Chikama et al., ${ }^{15}$ a He-Ne laser beam with power of $1.5 \mathrm{~mW}$ and wavelength of $632.8 \mathrm{~nm}^{15}$ was scanned across the specimen surface using an acoustic optic deflector (AOD) in the horizontal direction and a Galvano mirror in the vertical direction. For the latest version of HT-CLSM, VL2000DX-SVF17SP, manufactured by Lasertec Corporation $^{22}$ and Yonekura Manufacturing Corporation, ${ }^{23}$ a wavelength of $405 \mathrm{~nm}$ is used. As shown in Fig. 1, the scanning beam is focused on the sample surface via a polarizing plate, a long-focus objective lens, and a viewport covered with a quartz window. The reflection from the sample surface is passed through a polarizing beam splitter to a lens, and subsequently focused onto a charge-coupled device (CCD) camera positioned behind a pinhole. HT-CLSM can scan the surface at different focal distances and subsequently reconstruct an image of the sample surface in a three-dimensional plot with small $Z$ direction depth. Using the simpler approach with focusing at only one focal distance, the image acquisitions are much faster, and this is usually the operation mode applied for in situ studies at high temperatures. The excellent depth $(Z)$ resolution of about $0.01 \mu \mathrm{m}$ provided by the pinhole enables the distinction between flat areas and even shallow grooves or dimples on the sample surface. ${ }^{22,23}$ The lateral resolution of CLSM is limited by the wavelength of the laser and is about $0.15 \mu \mathrm{m}$. This means that the maximum useful magnification is on the order of 1000 times. For the latest version HTCLSM, VL2000DX-SVF17SP, the maximum magnification is $3000 \times .^{22,23}$ For further information on the working principles and instrumentation of HTCLSM, the reader is referred to Refs. 15 and 22-25.

\section{DETAILS OF OPERATION}

The maximum temperatures and heating rates depend on the capability of the halogen infrared (IR) heating lamp. According to the manufacturer, ${ }^{22,23}$ the maximum working temperature can be set to $1800^{\circ} \mathrm{C}$, the maximum heating rate can approach $1200^{\circ} \mathrm{C} / \mathrm{min}$, and rapid cooling at an average rate of $3000^{\circ} \mathrm{C} / \mathrm{min}$ at the higher temperatures can be obtained by forced cooling using He gas. To study surface phenomena in metallic samples, it is necessary to use a sample surface polished to mirror finish. Frequently used sample sizes are $4 \mathrm{~mm}$ and $8 \mathrm{~mm}$ in diameter to match the standard crucible size. ${ }^{22,23}$

The temperature of the furnace is controlled based on the primary thermocouple (TC) located at the bottom of the crucible. Typical temperature differences between the sample surface and the bottom of the crucible are about $20^{\circ} \mathrm{C}$ to $40^{\circ} \mathrm{C}$, depending on the sample material, sample thickness, and heating or cooling rate. The specification given here was evaluated for a low-carbon steel sample with $1 \mathrm{~mm}$ thickness, cooled at a rate between $3.6^{\circ} \mathrm{C} / \mathrm{min}$ and $678^{\circ} \mathrm{C} / \mathrm{min} .^{26}$ Because of this difference in temperature, it may be important to measure the temperature of the sample surface by welding a second TC on the sample surface. Another approach is to calibrate the temperature by performing melting experiments of metal reference 


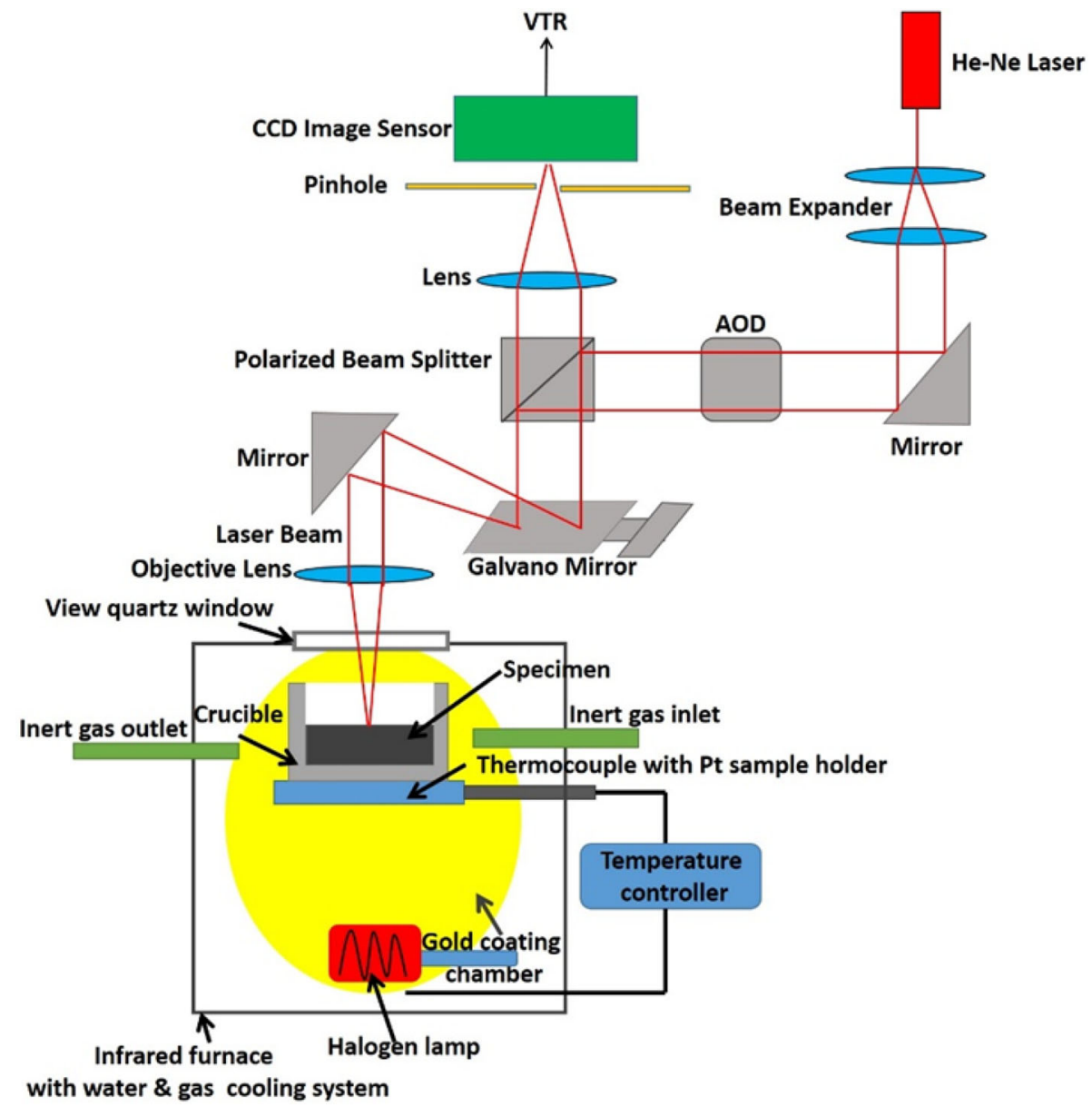

Fig. 1. Schematic illustration of high-temperature confocal laser scanning confocal microscopy (HT-CLSM).

samples with known melting temperatures; For example, lead, aluminum, copper, nickel, and iron can be melted in separate experiments under the same heating and cooling conditions.

It is important to prevent oxidation of the sample surface, since this would obscure the observations of the phenomenon of interest. Therefore, a vacuum system with rotary and/or diffusion pumps is installed. Purging of inert Ar gas with high purity is also available to decrease the oxygen content of the furnace atmosphere. Materials that are very sensitive to oxidation such as pure silicon ${ }^{27}$ and $\mathrm{Al}$ alloys ${ }^{28,29}$ require ultralow oxygen partial pressure $\left(P_{\mathrm{O} 2}\right)$, whereas steel samples are less sensitive and non-metallic oxide samples are not sensitive to $P_{\mathrm{O} 2}$. A mixed gas atmosphere with, e.g., $5 \% \mathrm{H}_{2}$ and ultrapure Ar gas, can be used to control $P_{\mathrm{O} 2}$ to about $10^{-15} \mathrm{~Pa}$ to $10^{-20} \mathrm{~Pa}$. However, high concentrations of $\mathrm{H}_{2}$ may damage the gold coating of the furnace chamber and the TC wire, thus $\mathrm{H}_{2}$ is only used when necessary. The experimental conditions are different in each study, hence the specific conditions should be referred to when discussing each work if relevant. For further information on the details of operating conditions, the reader is referred to Refs. 22 and 23.

\section{HT-CLSM STUDIES WITHIN OXIDE METALLURGY}

\section{Overview of In Situ Studies in Oxide Metallurgy by HT-CLSM}

In situ HT-CLSM observations of ferrite formation in steel date back to the work by Hanamura et al. ${ }^{30}$ in 1999. In their work, the starting temperature and morphology of polygonal ferrite $(\mathrm{PF})$ and Widmanstätten ferrite (WF) nucleated from oxides and sulfides as well as precipitation were successfully measured. They reported that $\mathrm{PF}$ started to precipitate at oxide particles at $773^{\circ} \mathrm{C}$ and that $\mathrm{WF}$ started to precipitate at $\mathrm{MnS}$ particles at $730^{\circ} \mathrm{C}$. The undercooling responsible for the difference in morphology between the ferrite formed at an oxide and at MnS was determined to be $43^{\circ} \mathrm{C} .{ }^{30}$ Phelan and coworkers investigated formation of $\mathrm{WF}$ in a lowcarbon steel grade. ${ }^{31,32}$ WF formed from the prior austenite grain boundary, but IGF formation from inclusion surfaces was not reported. Thereafter, Kikuchi et al. ${ }^{33-36}$ applied HT-CLSM to investigate the postsolidification microstructure refinement in low-carbon high-manganese steels through Ti deoxidation. Several issues, including austenite grain growth and decomposition, solidification structure, 

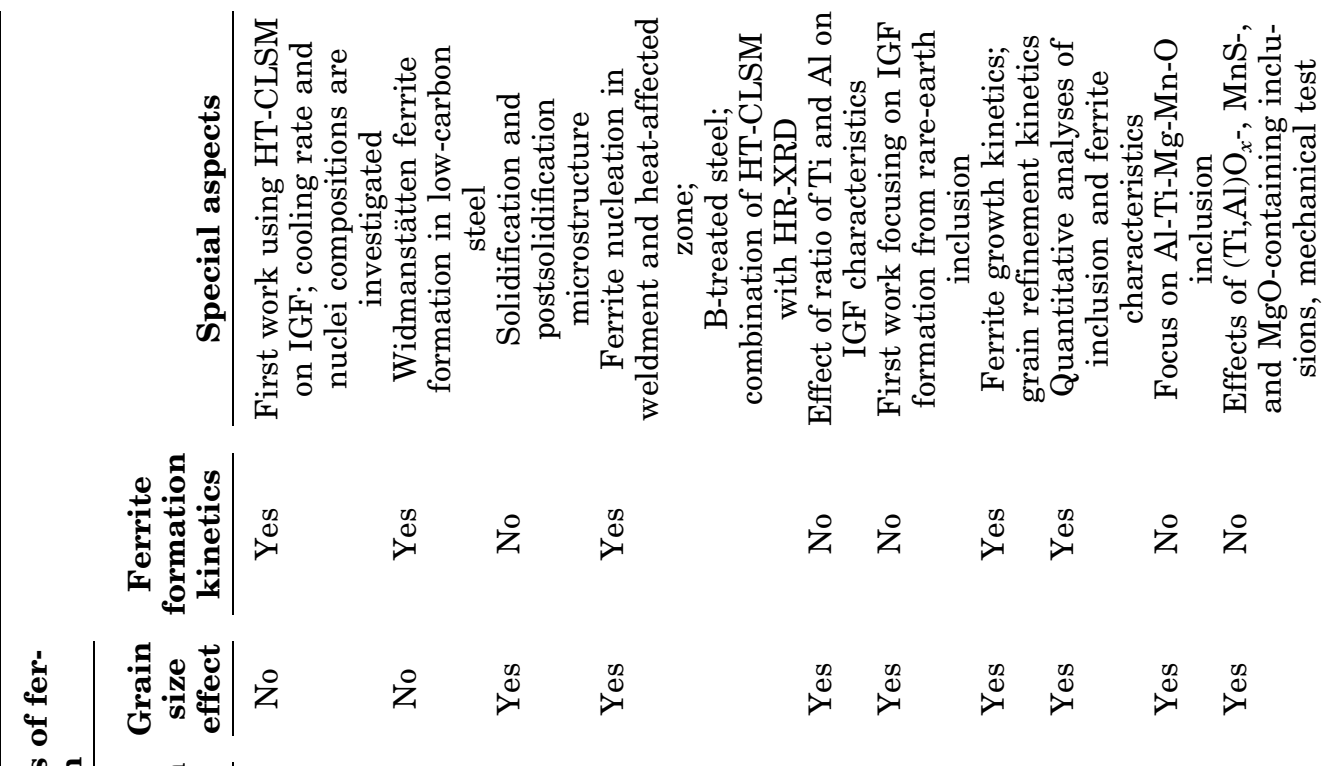

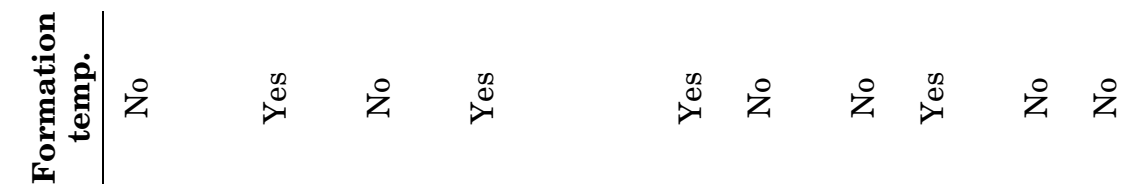

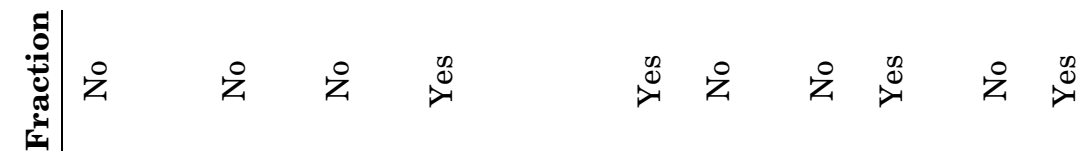

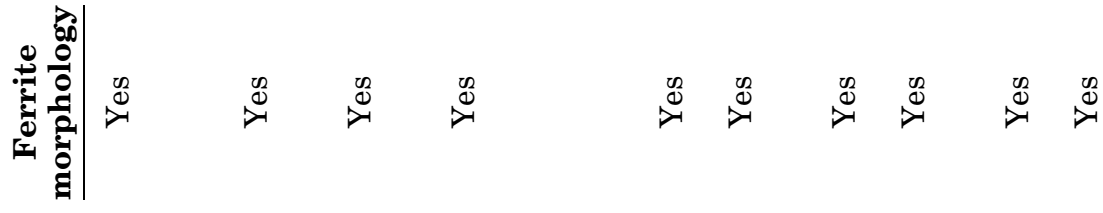

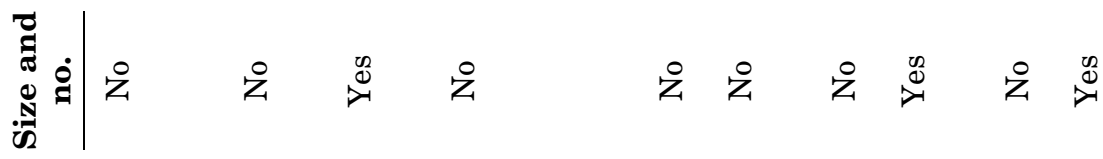

\begin{tabular}{|c|c|c|c|c|c|c|c|c|c|c|}
\hline & 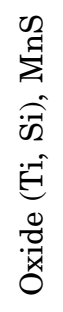 & 之 & 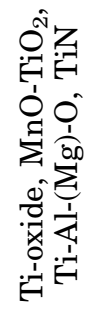 & 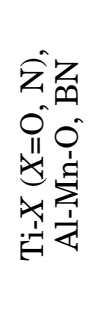 & 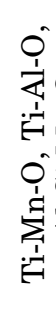 & 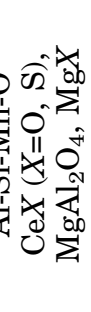 & $\underset{B}{Z}$ & 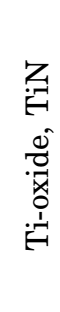 & 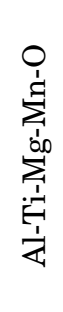 & 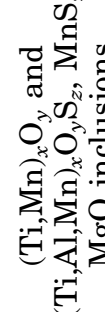 \\
\hline & ஓ् & 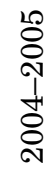 & 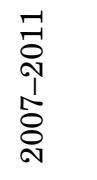 & $\begin{array}{l}m \\
\stackrel{9}{\circ} \\
\stackrel{1}{1} \\
\stackrel{-}{-1} \\
\stackrel{-}{0}\end{array}$ & 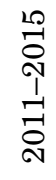 & 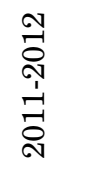 & 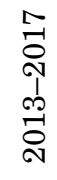 & 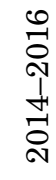 & $\stackrel{10}{\stackrel{10}{\circ}}$ & 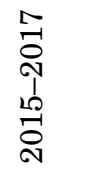 \\
\hline & 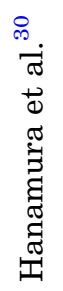 & 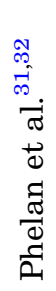 & 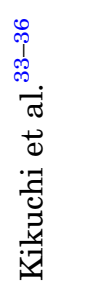 & 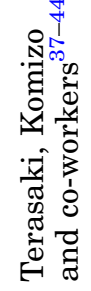 & 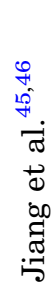 & 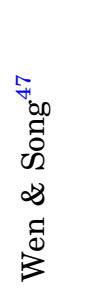 & 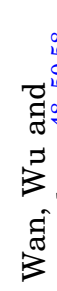 & & 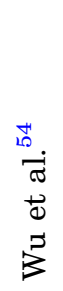 & 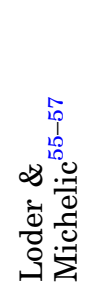 \\
\hline
\end{tabular}



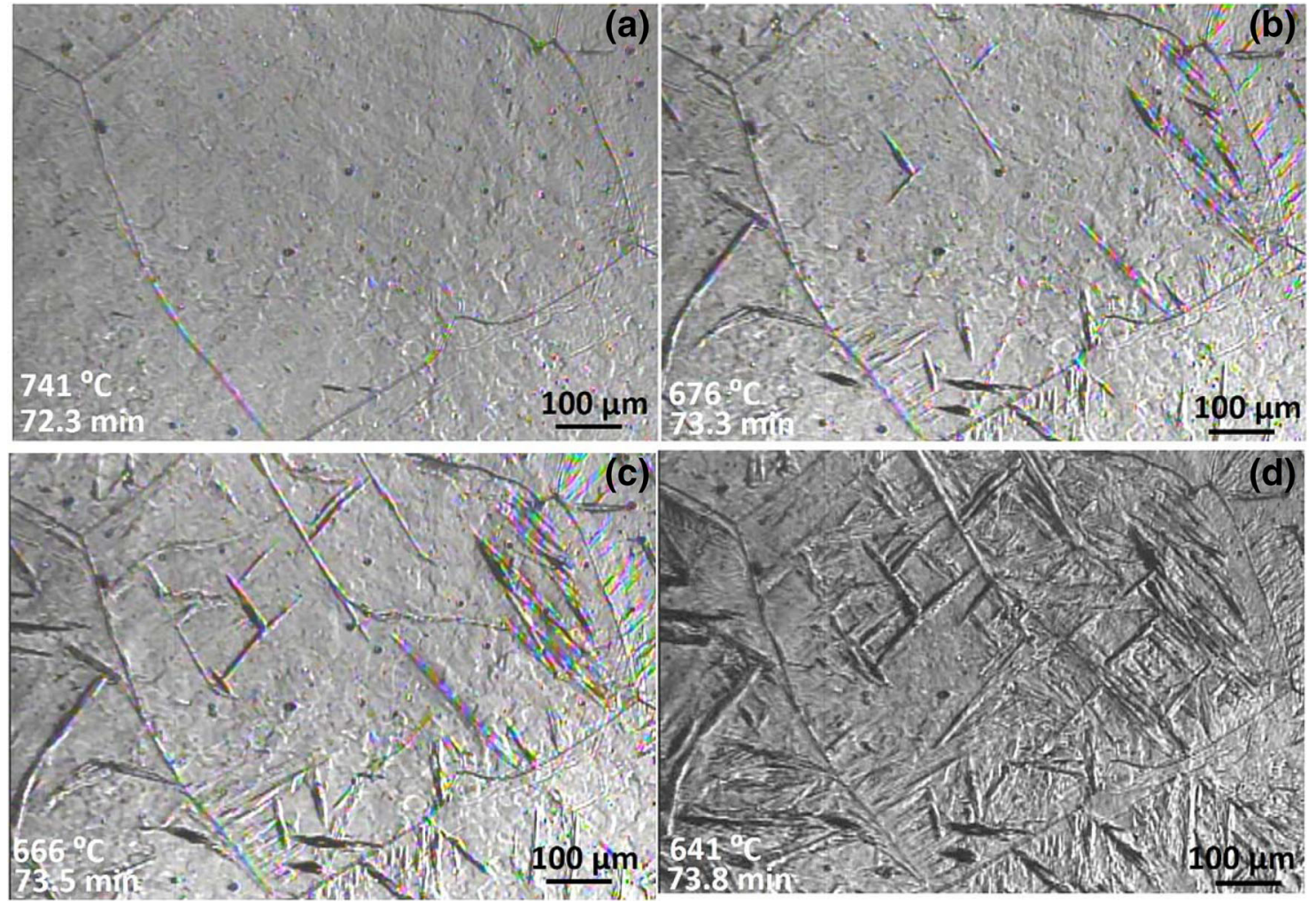

Fig. 2. Typical HT-CLSM images of IGF formation and growth in a steel with $\mathrm{TiO}_{2}$ addition. (a) GBF transformation starts at $741^{\circ} \mathrm{C}$, (b) IGF transformation starts at $676^{\circ} \mathrm{C}$, (c) GBF and IGF growth at $666^{\circ} \mathrm{C}$, and (d) transformations of GBF and IGF finish at $641^{\circ} \mathrm{C}$.

and secondary deoxidation particles, were studied. Terasaki, Komizo, and coworkers ${ }^{37-44}$ were the first to provide comprehensive quantitative analysis of the effect of inclusions on factors such as ferrite fraction, phase transition temperature, and grain size. Thereafter, Jiang et al. ${ }^{45,46}$ and Wen et al. ${ }^{47}$ followed this methodology and performed in situ observations of ferrite formation kinetics in steels containing Ti-Mn-O and Al-Si-Mn-O complex oxides as well as rare-earth inclusions. Wan, $\mathrm{Wu}$, and coworkers $^{48-50}$ observed grain refinement in HSLA steels containing TiN during heat treatments. Their heating and cooling profiles were chosen to simulate the coarse-grained heat-affected zone (CGHAZ) of weldments. $\mathrm{Mu}$ et al. ${ }^{26,51-53}$ performed another comprehensive in situ study on ferrite formation kinetics. The effects of the cooling rate, grain size, and inclusion composition on the ferrite fraction and phase-transition temperature were quantitatively investigated in inclusion-engineered steels containing TiN and Ti-oxide additions. The steel grades had carbon content varying between 0.2 wt.\% and 0.3 wt.\%. Note that the steel matrix and nuclei particle compositions were quite different from the results of previous studies. ${ }^{37-44}$ Moreover, a theoretical model based on classical nucleation theory was established to quantify the different potencies of nucleation sites. ${ }^{52,53}$ Subsequently, Wu et al. ${ }^{54}$ and Loder et al. ${ }^{55-57}$ performed in situ studies in steels after treatment with complex deoxidizers. Several complex oxides such as Al-Ti-Mg-Mn-O, $(\mathrm{Ti}, \mathrm{Mn})_{x} \mathrm{O}_{y}$, and $(\mathrm{Ti}, \mathrm{Al}, \mathrm{Mn})_{x} \mathrm{O}_{y} \mathrm{~S}_{z}$ were found to be effective nucleation sites. In their studies, both the inclusion and steel matrix characteristics were investigated. A summary of the available in situ studies of ferrite formation till 2017 is presented in Table I.

In literature, HT-CLSM has mainly been used to study the following parameters in situ during heat treatments: (i) ferrite fraction evolution, (ii) onset and completion of phase transformations, i.e., start and finish temperatures or times, (iii) grain coarsening, and (iv) IGF growth kinetics, such as twodimensional (2D) lengthening and widening of, e.g., ferrite. Examples of typical HT-CLSM images of GBF and IGF formation in a steel are given in Fig. 2. In this case, it is a steel with $\mathrm{TiO}_{2}$ additions which was heated to $1400^{\circ} \mathrm{C}$ then directly cooled at rate of $70^{\circ} \mathrm{C} / \mathrm{min}$. The next section uses the new data from this steel in combination with results from literature to discuss how HT-CLSM has contributed and can further contribute to understanding of ferrite formation within oxide metallurgy and also more generally to austenite decomposition in steels. More specifically, we discuss evolution of IGF, starting temperature of ferrite formation, austenite grain growth, and ferrite growth kinetics in continuous cooling experiments. 

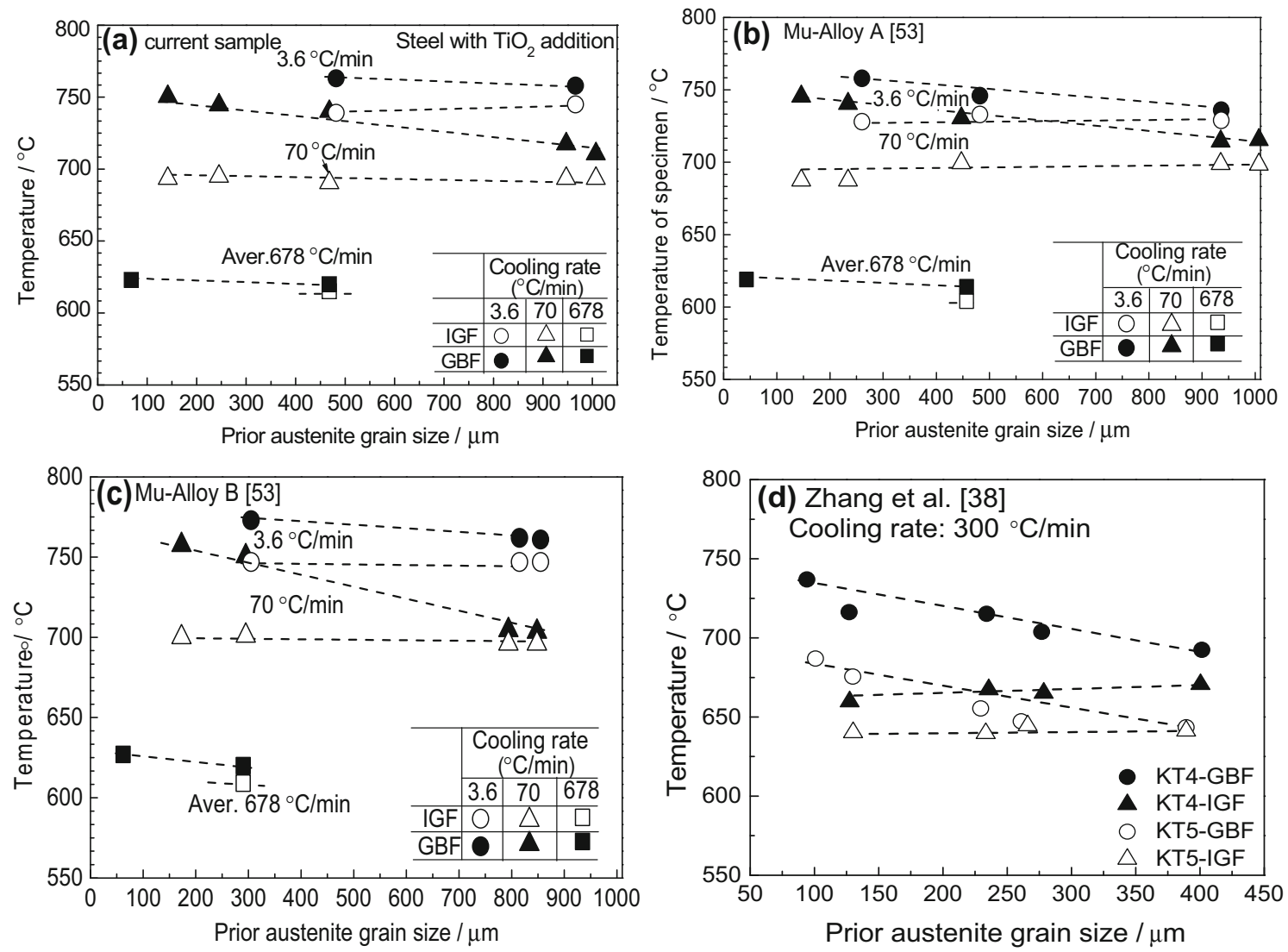

Fig. 3. Effect of prior austenite grain size and cooling rate on starting temperature of IGF and GBF formation in (a) the current steel with $\mathrm{TiO}_{2}$ addition, (b) alloy A and (c) alloy B taken from Ref. 53, and (d) data taken from Ref. 38.

\section{Starting and Finishing Temperatures of Phase Transformations}

The starting and finishing temperature of phase transformations can be directly observed by in situ HT-CLSM. Examples of observations on the starting temperatures of GBF and IGF affected by the prior austenite grain size (PAGS) can be seen in Fig. 3. There are a number of studies in literature on the starting temperatures of IGF $\left(T_{\mathrm{GBF}, \mathrm{s}}\right)$ and $\mathrm{GBF}$ $\left(T_{\mathrm{IGF}, \mathrm{s}}\right)$. Some of these results from literature are presented together with the new data for alloy A and $\mathrm{B}^{53}$ and KT4 and $5^{38}$ in Fig. 3. In Fig. 3a to c, the grain size was controlled by heating the samples to different maximum temperatures of $1200^{\circ} \mathrm{C}, 1250^{\circ} \mathrm{C}$, $1300^{\circ} \mathrm{C}$, and $1400^{\circ} \mathrm{C}$ without holding, and by further holding the samples at $1400^{\circ} \mathrm{C}$ from $0 \mathrm{~min}$ to 10 min. ${ }^{53}$ In Fig. 3d, the PAGS was increased by increasing the holding time from $0 \mathrm{~min}$ to $5 \mathrm{~min}$ at $1400^{\circ} \mathrm{C} .^{38}$ The alloys were subsequently cooled at different rates. The overall tendency is for $T_{\mathrm{IGF}, \mathrm{s}}$ to be independent of PAGS, whereas $T_{\mathrm{GBF}, \mathrm{s}}$ is about $20^{\circ} \mathrm{C}$ to $50^{\circ} \mathrm{C}$ lower for coarse compared with fine grains. It is also seen that IGF forms at a temperature about $20^{\circ} \mathrm{C}$ to $50^{\circ} \mathrm{C}$ lower compared with GBF. Moreover, both $T_{\mathrm{IGF}, \mathrm{s}}$ and $T_{\mathrm{GBF}, \mathrm{s}}$ decrease with increasing cooling rate. As discussed in "Overview of In Situ Studies in Oxide Metallurgy by HT-CLSM" section, the ferrite formation behavior for the steels with $\mathrm{Ti}_{2} \mathrm{O}_{3}$ and $\mathrm{TiO}_{2}$ additions is similar. The reason is that $\mathrm{TiO}_{x}$ inclusions are formed in both steel grades, $x$ ranges from 1.5 to 1.8 , and these act as preferential nucleation sites. ${ }^{51}$ Thus, the $T_{\mathrm{IGF}, \mathrm{s}}$ of these steels are quite close to each other.

Since HT-CLSM can only be used to observe the phase-transition temperature on the sample surface, a hybrid methodology combining HT-CLSM and differential scanning calorimetry (DSC) has been established to study all the austenite decomposition products, i.e., IGF, GBF, and pearlite. ${ }^{26}$ This can be combined with investigations of the sample surface and bulk microstructures using, e.g., electron backscatter diffraction (EBSD). An example of the application of this methodology is presented here for the present alloys. DSC results using different cooling rates are shown in Fig. 4a and b. In Fig. 4, the first inflection point is identified as the starting temperature of ferrite formation, named $T_{\mathrm{F}, \mathrm{s}}$; subsequently, the second and third inflection points are identified as the starting and finishing temperatures of pearlite formation, named $T_{\mathrm{P}, \mathrm{s}}$ and $T_{\mathrm{P}, \mathrm{f} .}$ Note that DSC can only detect $T_{\mathrm{F}, \mathrm{s}}$, but by combining it with HT-CLSM, it was possible to also identify $T_{\mathrm{GBF}, \mathrm{s}}$ and $T_{\mathrm{IGF}, \mathrm{s}}$. The 

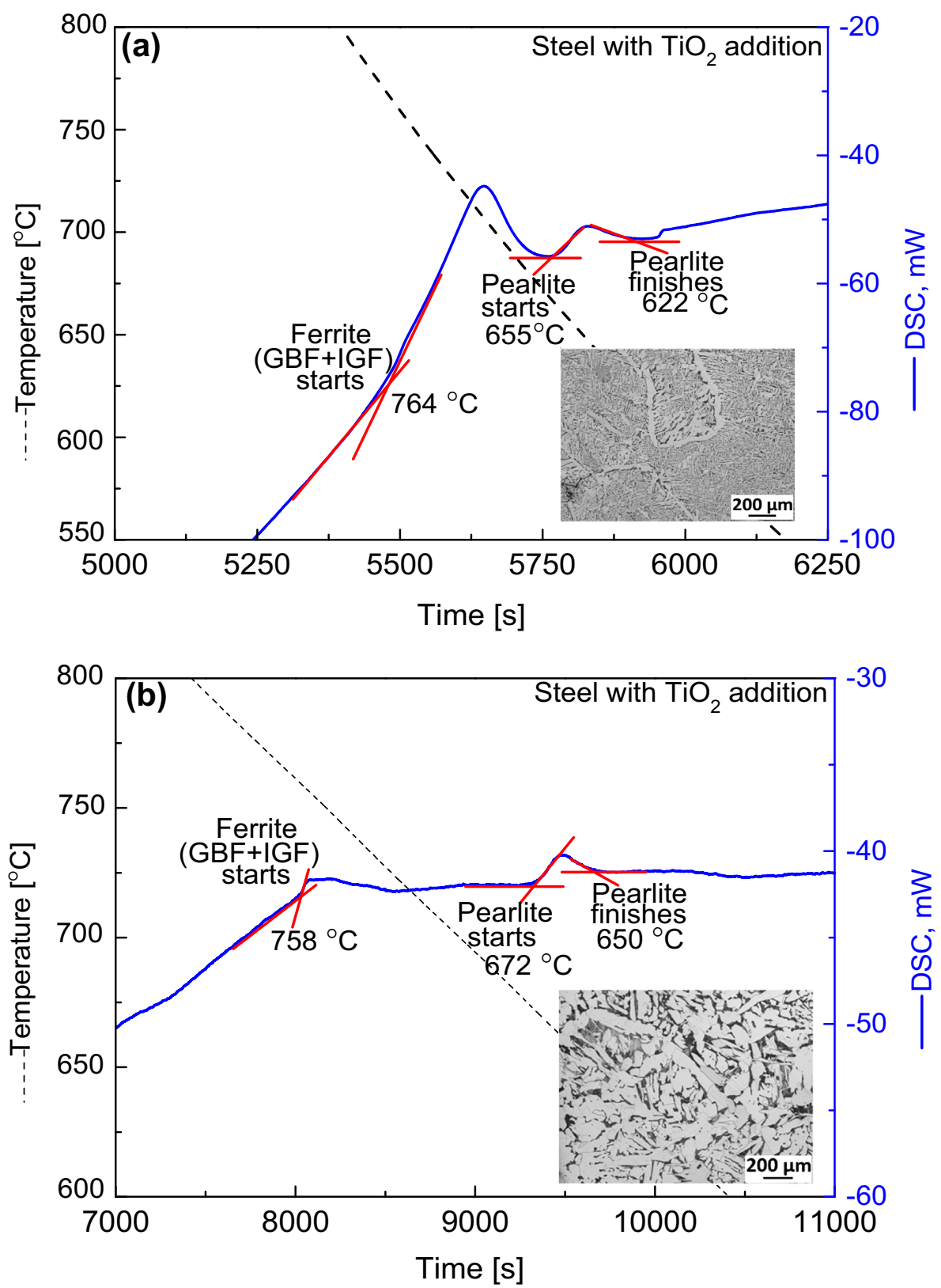

Fig. 4. DSC analysis of current steel with $\mathrm{TiO}_{2}$ addition, cooled at rate of (a) $18.3^{\circ} \mathrm{C} / \mathrm{min}$ and (b) $3.6^{\circ} \mathrm{C} / \mathrm{min}$.

final continuous cooling transformation (CCT) diagram is shown in Fig. 5. It can be seen from the EBSD micrographs that the microstructure becomes finer with increasing cooling rate. These types of CCT diagrams can clearly aid selection of the heat treatment cycle in oxide metallurgy.

\section{Evolution of Fraction of Intragranular Ferrite (IGF)}

The evolution of the fraction of IGF in a specific steel grade depends on two factors, according to literature. Firstly, the fraction of IGF depends on the parent austenite grain size (PAGS). ${ }^{38,53}$ Secondly, the IGF fraction evolution clearly depends on the cooling rate in continuous cooling experiments.

Considering the PAGS first, the fraction of IGF increases with increasing grain size, disregarding other factors such as the composition of inclusions and steel grade. The reason has been reported to be that a larger PAGS provides a larger physical space for formation of IGF. ${ }^{59}$ Examples of this behavior are given in Fig. 6 , where results from our own work on a steel with $\mathrm{TiO}_{2}$ addition are shown together with results from literature for low-alloy steels with $\mathrm{Ti}_{2} \mathrm{O}_{3}$ addition (alloy A), ${ }^{53}$ with $\mathrm{TiN}$ 


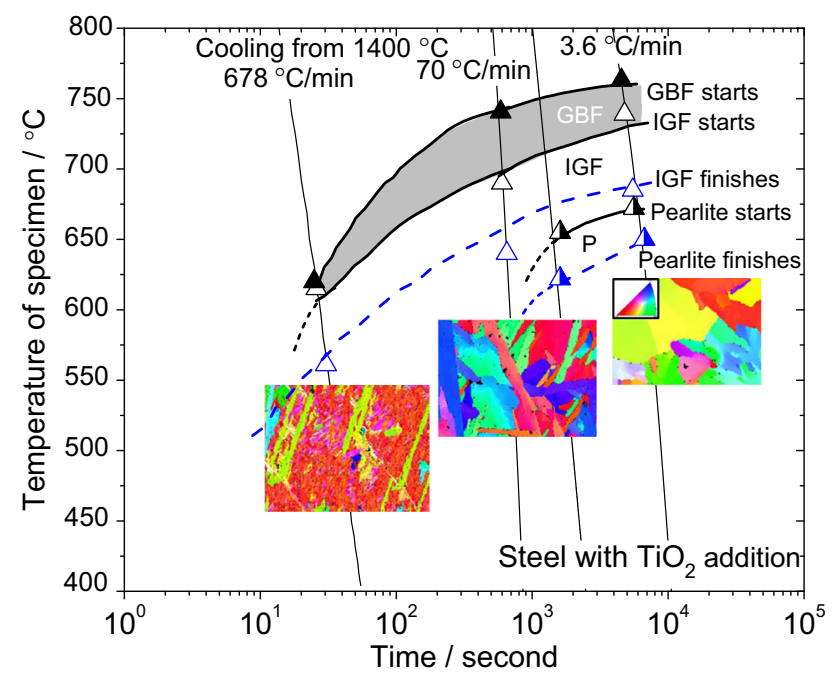

Fig. 5. Schematic CCT diagram of the steel with $\mathrm{TiO}_{2}$ addition, measured by HT-CLSM, DSC, and EBSD. addition (alloy B), ${ }^{53}$ with Ti (KT4) and with Ti-Balloying (KT5) where $\mathrm{TiX}\left(\mathrm{TiN}\right.$ and $\mathrm{TiO}_{x}$ ) and $\mathrm{Mn}$ Al-O exist. ${ }^{38}$

The effect of cooling rate on IGF formation is also presented in Fig. 6. It can be seen in Fig. 6a and b that, when the cooling rate is varied between $3.6^{\circ} \mathrm{C} /$ $\min , 70^{\circ} \mathrm{C} / \mathrm{min}$, and $678^{\circ} \mathrm{C} / \mathrm{min}$, the area fraction of IGF increases with increasing cooling rate from $3.6^{\circ} \mathrm{C} / \mathrm{min}$ to $70^{\circ} \mathrm{C} / \mathrm{min}$. However, the IGF fraction is lowered when increasing the cooling rate further to $678^{\circ} \mathrm{C} / \mathrm{min}$. The reason for this is competing phase transformations, where low cooling rates promote GBF, whereas high cooling rates promote martensitic transformation. Hence, both cooling rate and alloy composition must be considered to evaluate whether a microstructure with high fraction of IGF will be obtained. It can also be noted that the results for the steel with $\mathrm{TiO}_{2}$ addition in Fig. 6a are closely related to those of alloy $\mathrm{A}$ with $\mathrm{Ti}_{2} \mathrm{O}_{3}$ addition in Fig. 6b. As mentioned above, this is because the
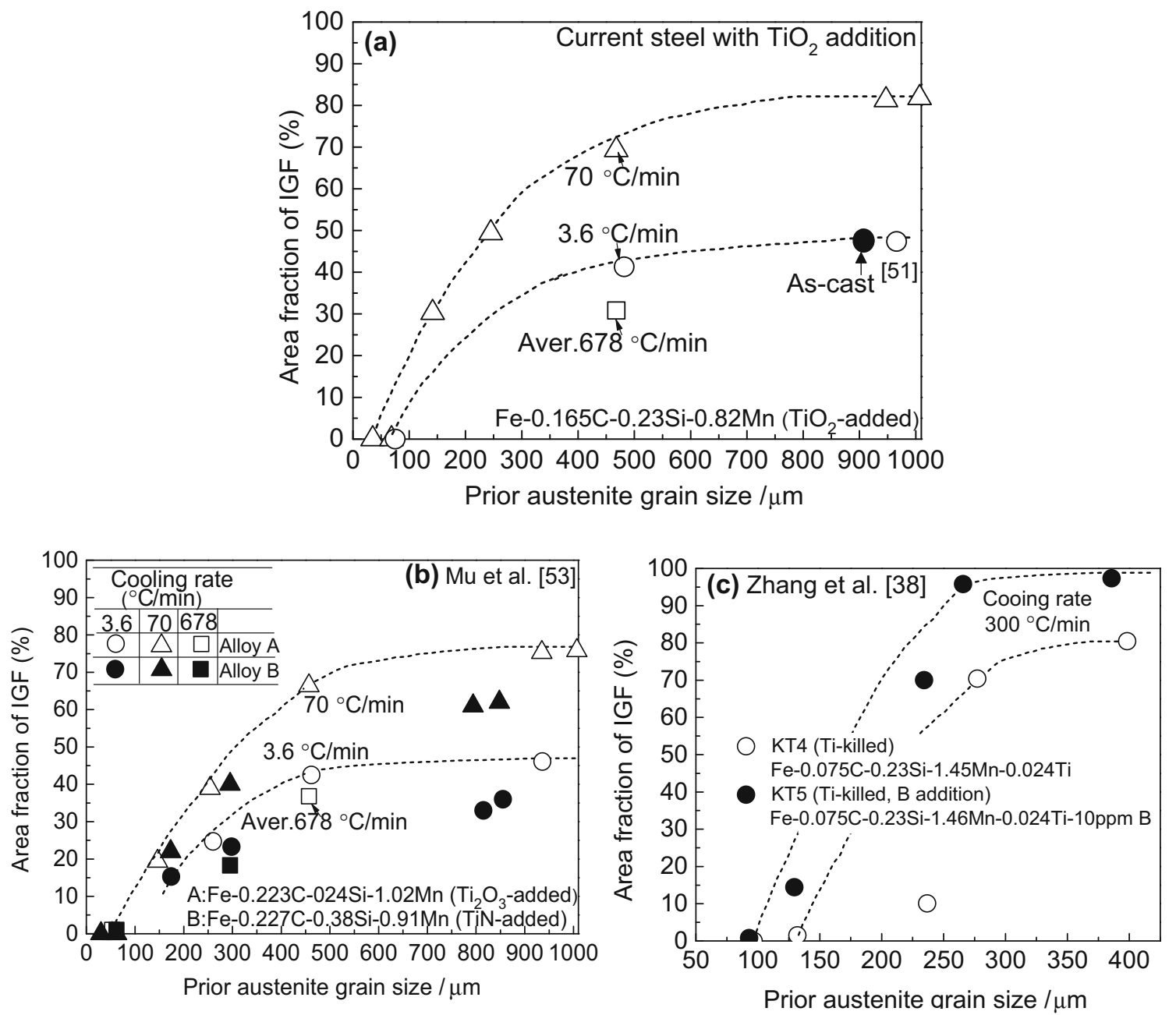

Fig. 6. Effect of prior austenite grain size and cooling rate on fraction of IGF in (a) current steel with $\mathrm{TiO}_{2}$ addition and in literature data published by (b) Mu et al..$^{53}$ and (c) Zhang et al. ${ }^{38}$ 

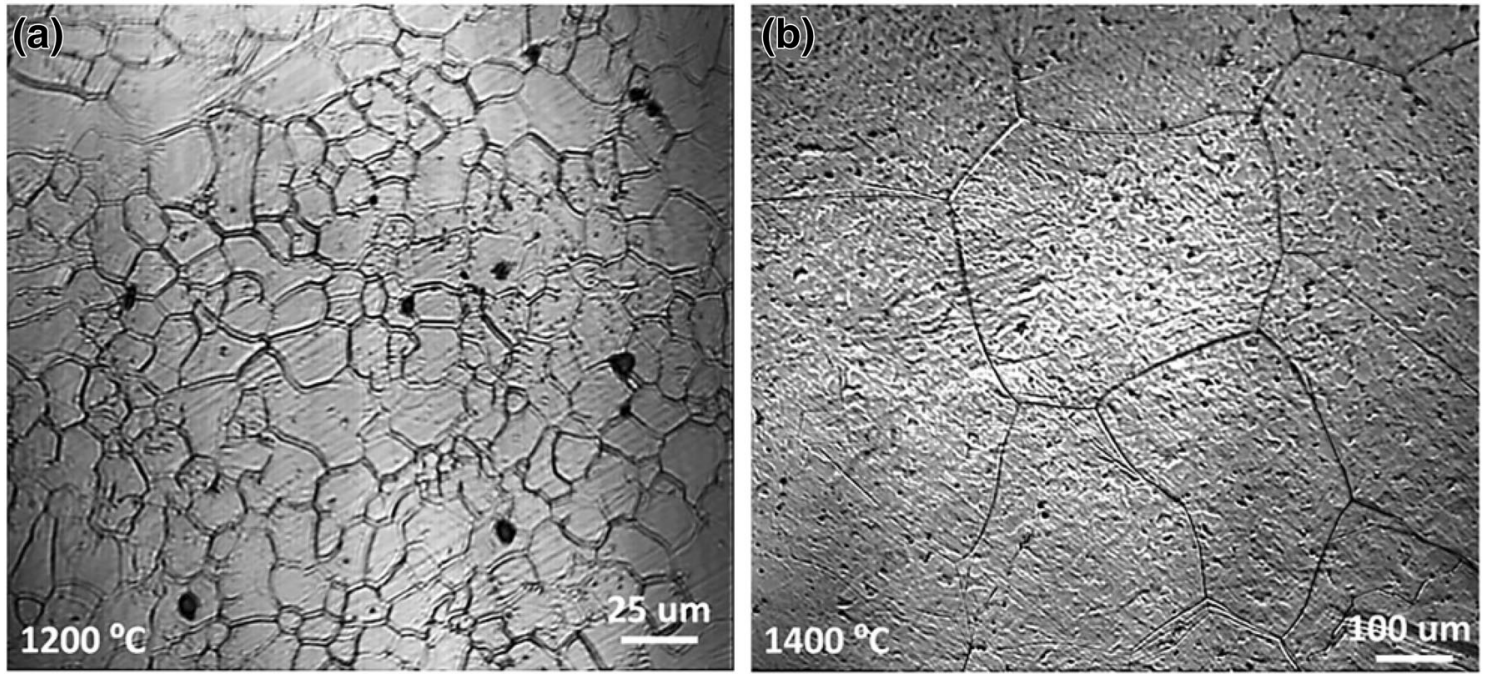

Fig. 7. Typical HT-CLSM images of increase of prior austenite grain size by heating samples and (a) $1200^{\circ} \mathrm{C}$ and (b) $1400^{\circ} \mathrm{C}$ at a rate of $20^{\circ} \mathrm{C} /$ min.

inclusions that are acting as effective nucleation sites are the same in both steels and the slight differences are instead related to the minor difference in matrix composition. ${ }^{51}$ It should also be noted that, when the cooling rate is $300^{\circ} \mathrm{C} / \mathrm{min}$, as in Fig. 6c, the increase of the IGF fraction with PAGS is steeper, thus the effect of PAGS is negligible above 250 microns, whereas for the slower cooling rate of $70^{\circ} \mathrm{C} / \mathrm{min}$ in Fig. $6 \mathrm{a}$ and $\mathrm{b}$, there is a difference with PAGS up to about 500 microns.

\section{Austenite Grain Size Control}

It is important for the design of an appropriate final microstructure in oxide metallurgy that the parent austenite grain size can be controlled. The transformation to austenite and the coarsening of the austenite grains can also be followed by in situ HT-CLSM due to grain boundary grooving generating a topographic contrast. Figure 7 shows typical HT-CLSM images of the coarsened austenite grain size in steel after heating to $1200^{\circ} \mathrm{C}$ and $1400^{\circ} \mathrm{C}$ at rate of $20^{\circ} \mathrm{C} / \mathrm{min}$. It is clear that coarsening is stimulated by high temperature and prolonged soaking, but the details of specific alloys and heating and cooling cycles can be investigated. The effect of holding temperature on PAGS in the current alloy and in literature data by $\mathrm{Mu}$ et al. ${ }^{53}$ is summarized in Fig. 8a. Moreover, the effect of holding time at $1400^{\circ} \mathrm{C}$ on PAGS from a previous study by Zhang et al. ${ }^{38}$ is summarized in Fig. $8 \mathrm{~b}$. The chemical compositions of the steels presented in Fig. 8 are summarized in Table II. Note that similar steel compositions exhibit similar austenite graincoarsening behavior (see the current alloy and alloy
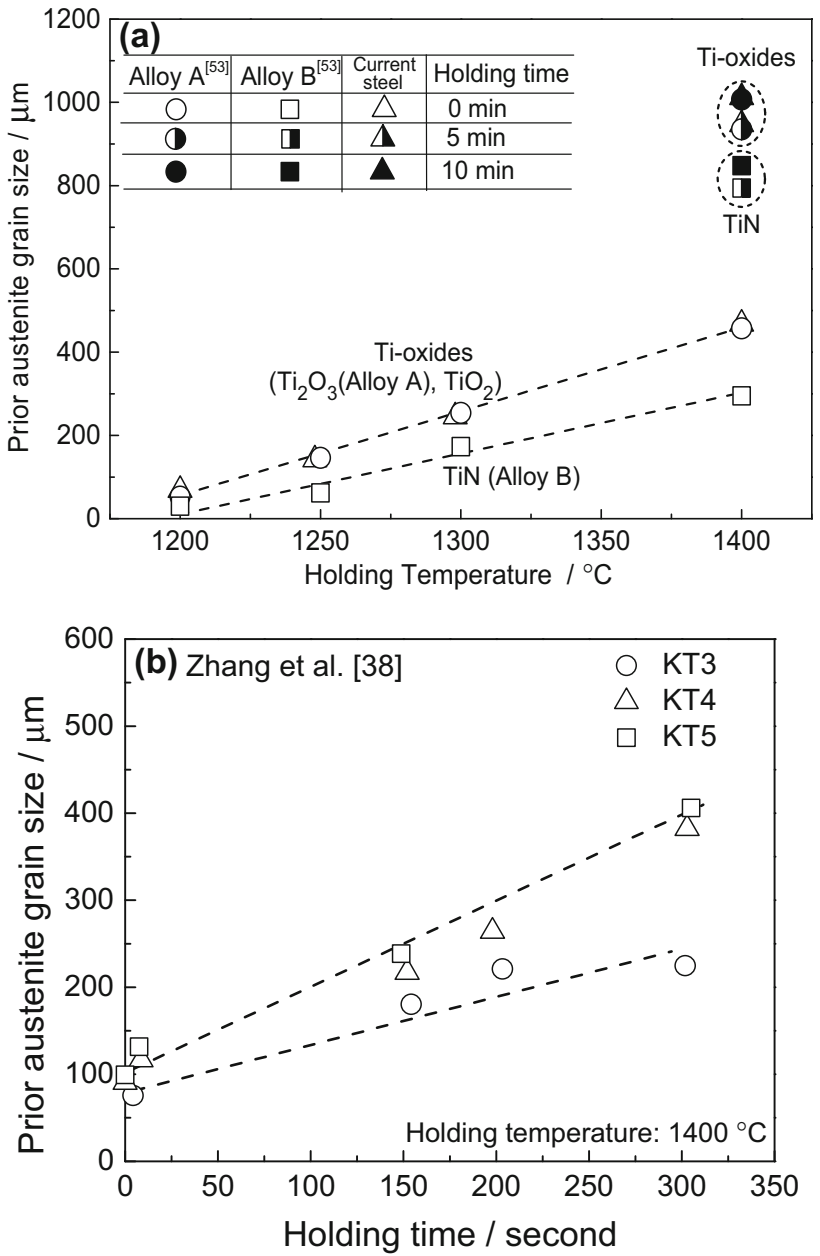

Fig. 8. Effect of (a) temperature ${ }^{53}$ and (b) holding time $^{38}$ on prior austenite grain size. 
Table II. Chemical compositions of steels presented in Fig. 8

\begin{tabular}{|c|c|c|c|c|c|c|c|c|c|}
\hline Steel & $\mathbf{C}$ & $\mathbf{S i}$ & Mn & $\mathbf{A l}$ & $\mathbf{T i}$ & $\mathbf{S}$ & $\mathbf{N}$ & $\mathbf{O}$ & Comments \\
\hline Current sample & 0.165 & 0.23 & 0.82 & $<0.002$ & 0.010 & 0.008 & 0.016 & 0.0066 & $\mathrm{TiO}_{2}$ addition \\
\hline $\mathrm{Mu}-$ Alloy $\mathrm{A}^{53}$ & 0.223 & 0.24 & 1.02 & 0.002 & 0.013 & 0.009 & 0.017 & 0.0072 & $\mathrm{Ti}_{2} \mathrm{O}_{3}$ addition \\
\hline Mu-Alloy $\mathrm{B}^{53}$ & 0.227 & 0.38 & 0.91 & $<0.002$ & 0.008 & 0.009 & 0.029 & 0.0071 & TiN addition \\
\hline Zhang-KT3 ${ }^{38}$ & 0.075 & 0.23 & 1.48 & 0.027 & 0.013 & 0.003 & 0.0047 & 0.001 & Al-killed (4 ppm B) \\
\hline Zhang-KT $4^{38}$ & 0.075 & 0.23 & 1.45 & $<0.001$ & 0.018 & 0.003 & 0.0036 & 0.002 & Ti-killed (1 ppm B) \\
\hline Zhang-KT5 $5^{38}$ & 0.075 & 0.23 & 1.46 & $<0.001$ & 0.024 & 0.003 & 0.0042 & 0.002 & Ti-killed, $\mathrm{B}$ addition (10 ppm $\mathrm{B}$ ) \\
\hline
\end{tabular}

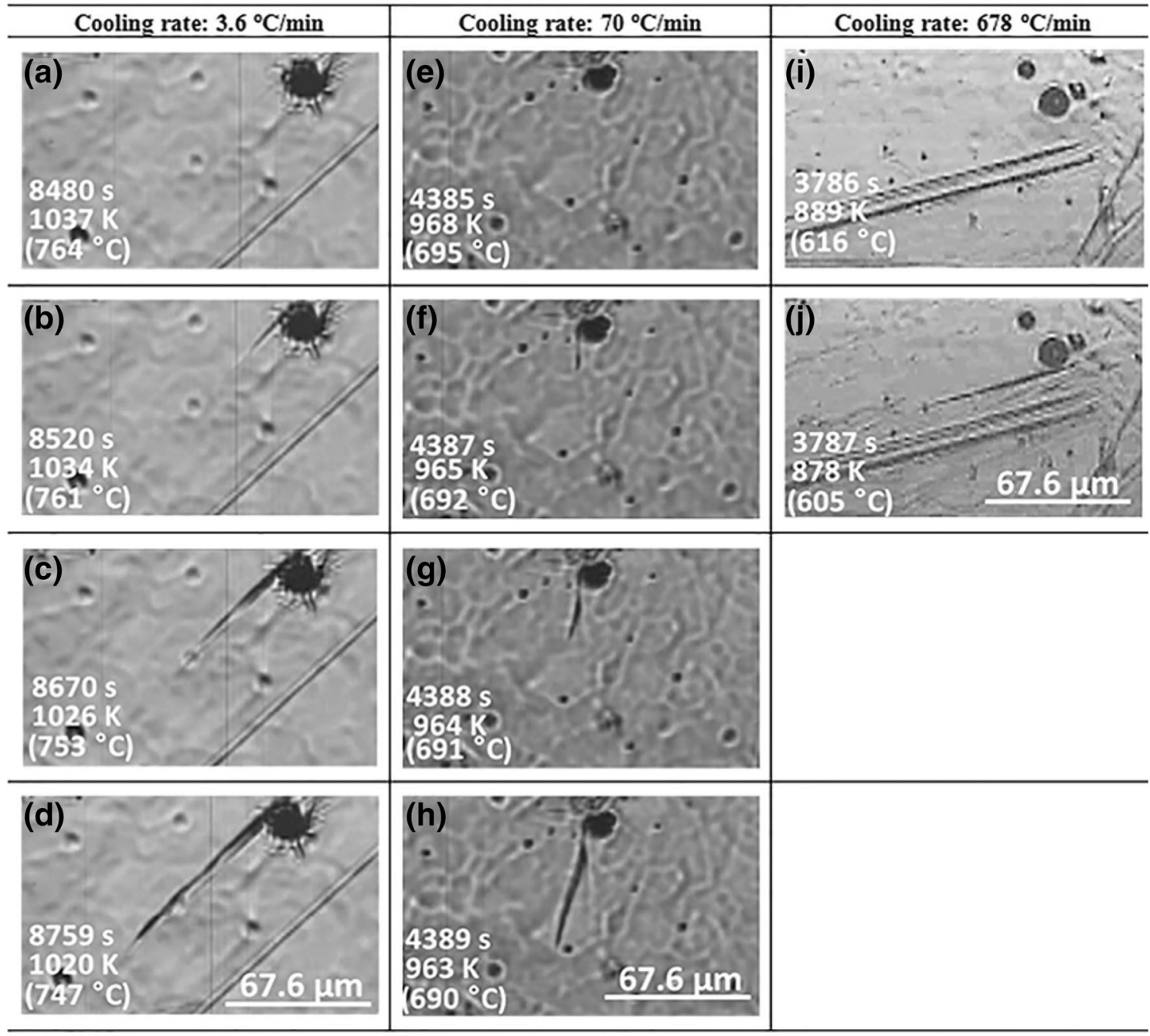

Fig. 9. Typical HT-CLSM images of IGF growth in the steel with $\mathrm{TiO}_{2}$ addition for cooling rate of $(\mathrm{a}-\mathrm{d}) 3.6^{\circ} \mathrm{C} / \mathrm{min},(\mathrm{e}-\mathrm{h}) 70^{\circ} \mathrm{C} / \mathrm{min}$, and $(\mathrm{i}, \mathrm{j})$ $678^{\circ} \mathrm{C} / \mathrm{min}$.

A in Ref. 53). However, the pinning effect of TiN is obvious in alloy $\mathrm{B}$, and it therefore has a significantly smaller PAGS. Zhang et al. ${ }^{38}$ also investigated the pinning effect of $\mathrm{BN}$, which was also strong, as evidenced by their KT5 sample with smaller PAGS at each holding condition. As a general observation in oxide metallurgy, it should also be mentioned that, in order to control the toughness of the coarse-grained heat-affected zone
(CGHAZ) of weldments, the austenite grain size should be controlled to a moderate value, somewhere between $100 \mu \mathrm{m}$ to $400 \mu \mathrm{m}$, according to HTCLSM results published to date. ${ }^{38,53}$ If it is less than $100 \mu \mathrm{m}$, IGF formation is not sufficient, whereas if it is over $400 \mu \mathrm{m}$, the large grain size can lead to low toughness. The grain size in CGHAZ is affected mainly by the heat input and must be controlled during welding. 


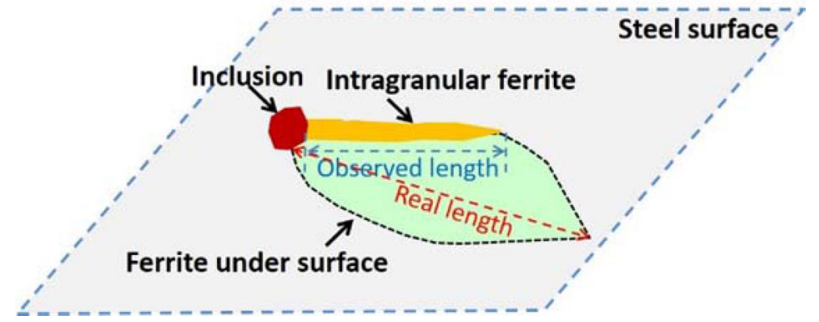

Fig. 10. Schematic illustration of difference between measured and actual length of an IGF unit.
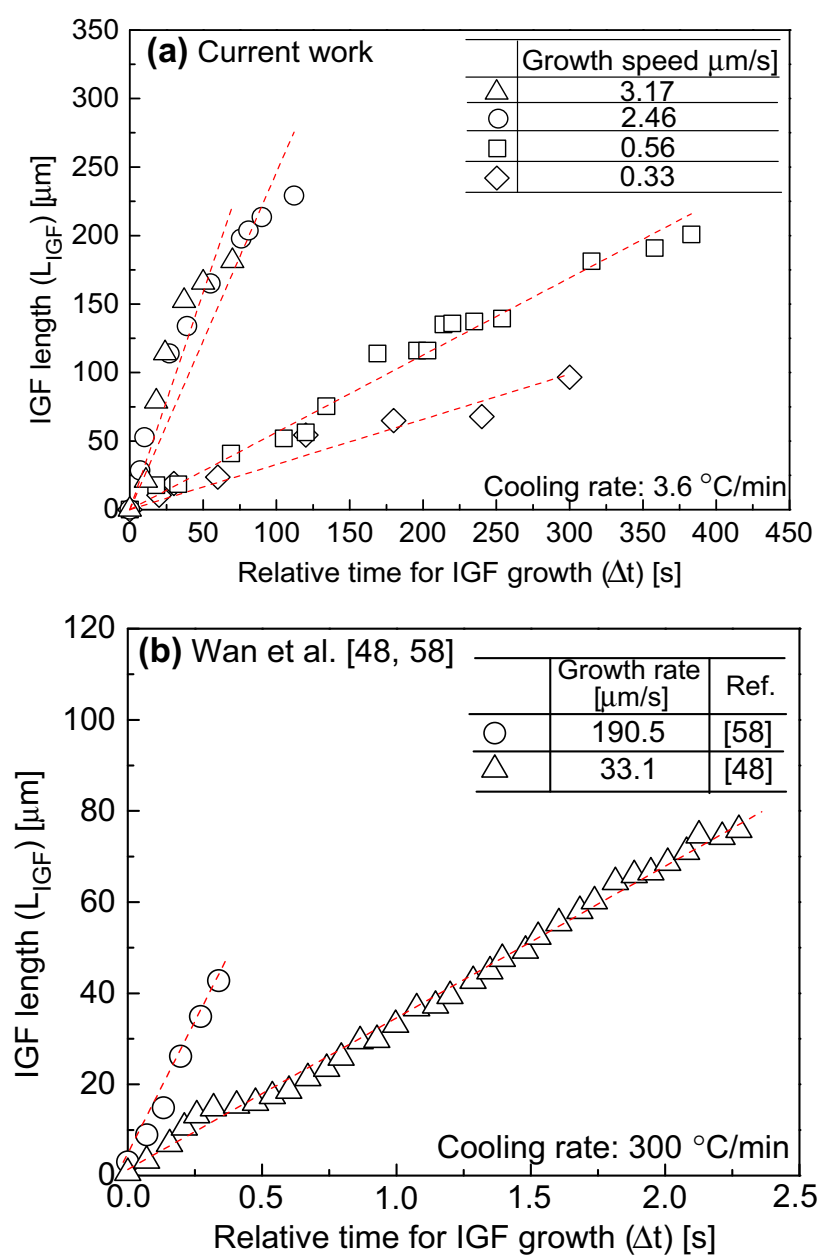

Fig. 11. Length of IGF unit against relative time in (a) current steel cooled at $3.6^{\circ} \mathrm{C} / \mathrm{min}$ and (b) steel cooled at $300^{\circ} \mathrm{C} / \mathrm{min}$ reported by Wan et al. ${ }^{48,58}$

\section{Ferrite Growth Kinetics}

Figure 9 shows typical images of the IGF growth kinetics in the steel with $\mathrm{TiO}_{2}$ addition for three selected cooling rates. Based on these images, the length of IGF lath at different cooling times can be measured, and subsequently the slope of the fit line connecting these data points corresponds to the IGF growth speed. These types of results have also been reported by Wan et al. ${ }^{48,58}$ based on HT-CLSM measurements. Note that the growth direction of IGF may not be parallel to the specimen surface, and it may be growing beneath the surface. A schematic illustration of the real and observed growth rate of IGF is presented in Fig. 10. In order to know the actual growth speed of IGF, a plausible methodology using only HT-CLSM can be to collect several IGF growth rates from the same alloy with the same cooling condition. The maximum value can be considered as the actual growth speed, as seen in the example in Fig. 11a. Note that the "maximum value" is currently decided in a somewhat ad hoc manner, but it is the intention of the authors to present more sophisticated analysis of the maximum value of the ferrite growth rate (actual growth rate) in future work. The growth rate of IGF reported by Wan et al. ${ }^{48,58}$ is also summarized in Fig. $11 \mathrm{~b}$. It is seen that this speed ranges between $33.3 \mu \mathrm{m} / \mathrm{s}$ to $190 \mu \mathrm{m} / \mathrm{s}$, and that the maximum value can be considered as the actual one. In addition, the growth rate of IGF reported by Wan et al. ${ }^{48,58}$ is over 60 times faster than that in the current sample, which is due to the much faster cooling rate $\left(300^{\circ} \mathrm{C} / \mathrm{min}\right)$ used in their work compared with the current value of $3.6^{\circ} \mathrm{C} / \mathrm{min}$. This research topic will be investigated in depth in future work by the authors. Besides the current methodology to detect ferrite growth kinetics based on only HT-CLSM measurements, further investigations in three-dimensional characterization, in conjunction with in situ observation, can be considered to understand the difference in the IGF growth kinetics on the specimen surface and in the bulk.

\section{Opportunities and Challenges in HT-CLSM for Oxide Metallurgy}

The unique benefit of HT-CLSM is its capability for in situ observations of surfaces up to about $1800^{\circ} \mathrm{C}$ with relatively rapid heating and cooling rates. These types of conditions are difficult to achieve when using other in situ microscopy techniques such as in situ transmission electron microscopy (TEM) or in situ scanning electron microscopy (SEM). The fastest cooling rate for state-of-the-art HT-CLSM today is approximately $3000^{\circ} \mathrm{C} / \mathrm{min}$ at high temperatures, which fulfills the requirement to mimic the conditions in many metallurgical processes and for solidification of metals. However, the cooling rate drops significantly at lower temperatures that are relevant for studies of solid-state phase transformation in steels; For example, it is not possible to study the martensitic phase transformation or to study low-temperature phase transformations such as bainite in isothermal conditions in many low-alloy steels, since their hardenability is too low. If a more powerful cooling system could be implemented to increase the cooling rate to say about $100^{\circ} \mathrm{C} / \mathrm{s}$, it would open up new application areas for HT-CLSM. 
HT-CLSM only provides images of the surface of the material investigated. This can sometimes be a problem, since surface behavior may differ from the bulk behavior. An example was given in "Ferrite Growth Kinetics" section, considering the stereology issue for the growth rate of IGF. Future work should try to improve the methodologies to analyze, e.g., the growth rate of a three-dimensional (3D) object from a 2D image, and complementary characterization techniques may assist this work. Reconstructive phase transformations such as pearlite and allotriomorphic ferrite formation are much more difficult to investigate than displacive transformations. The reason is that displacive transformations in steels result in clear surface relief, whereas this is not the case for reconstructive transformations. Therefore, for example, pearlite can only be seen in some cases as a faint contrast, and in other cases, e.g., when the surface is oxidized somewhat, it will obscure the pearlite observations.

A great development for HT-CLSM would be to enable more analytical information in connection with surface observations; For example, it would be very valuable to be able to study crystallography and chemistry simultaneously. This could possibly be achieved by, e.g., micro-focused x-ray diffraction and fluorescence, respectively. In large-scale facilities, i.e., synchrotrons, this type of hybrid methodology has already been implemented where timeresolved synchrotron x-ray diffraction (TRXRD) has been combined with HT-CLSM. This could most likely also be achieved on laboratory scale, since the high penetration of hard x-rays is not important or even desirable when HT-CLSM is probing only the surface.

Another issue that is more difficult to solve is the resolution limitation of HT-CLSM, which is in principle on the microscale and physically limited by the wavelength of the laser light. This resolution is good enough for the majority of process metallurgical research, e.g., non-metallic inclusion motion behavior in liquid metal and metal droplet in refining reactions, but this issue still limits its application in physical metallurgy, for example, for observing growth of fine precipitates.

The current application of HT-CLSM in metallurgy mainly focuses on ferrous materials, and it is foreseen that also non-ferrous metallurgy could benefit significantly as well, for instance, observing the solidification, metallic cluster dissolution, and melting in aluminum and titanium alloys. Another alloy category where so far no HT-CLSM studies have been reported is high-entropy alloys, e.g., FeNiCoCrMn- $x$ multicomponent alloys. Their hightemperature interfacial phenomena should also be of great interest. Another area of interest for HTCLSM could be solidification in additive manufacturing, since heating of the metal surface by the halogen lamp and the solidification process of the metal surface in the HT-CLSM could potentially mimic AM processing reasonably well.

\section{CONCLUSION}

HT-CLSM has proven to be a robust tool for in situ real-time observations of high-temperature phenomena related to metallurgical processes such as non-metallic inclusion motion behavior in liquid metal and their dissolution behavior in liquid slag, crystal growth during solidification as well as austenite decomposition, and ferrite growth in physical metallurgy. Even if this methodology has several limitations, numerous topics in metallurgical research have been investigated effectively using HT-CLSM. The present review provides a summary of selected insights gained from both literature and new results on austenite decomposition within the field of oxide metallurgy or inclusion engineering using HT-CLSM. Opportunities for developing HT-CLSM by establishing hybrid methodologies in combination with other characterization methodologies as well as expanding its applications in related neighboring fields of manufacturing are suggested.

\section{ACKNOWLEDGEMENTS}

W.M. and P.H gratefully acknowledge Jernkontoret, the Swedish Steel Producers' Association, for financing this work. W.M. also wants to thank The Swedish Foundation for International Cooperation in Research and Higher Education (STINT) for financial support by granting a Postdoctoral Transition Grants for Internationalisation (PT 20177330).

\section{OPEN ACCESS}

This article is distributed under the terms of the Creative Commons Attribution 4.0 International License (http://creativecommons.org/licenses/by/4.0/ ), which permits unrestricted use, distribution, and reproduction in any medium, provided you give appropriate credit to the original author(s) and the source, provide a link to the Creative Commons license, and indicate if changes were made.

\section{REFERENCES}

1. L. Zhang and B.G. Thomas, Metall. Mater. Trans. B 37, 733 (2006).

2. L. Zhang and B.G. Thomas, ISIJ Int. 43, 271 (2003).

3. S.R. Story, R.J. Fruehan, T.J. Piccone, and M. Potter, Iron Steel Technol. 1, 163 (2004).

4. T.A. Engh, H. Sandberg, A. Hultkvist, and L.G. Norberg, Scand. J. Metall. 1, 12 (1972).

5. J. Takamura and S. Mizoguchi, in Metallurgy of oxides in steels-1: Roles of oxides in steels performance (Proc. 6th Int. Iron and Steel Cong. 1990, ISIJ: Nagoya, Japan), pp. 591597.

6. S. Mizoguchi and J. Takamura, in Metallurgy of oxides in steels-2: control of oxides as inoculants (Proc. 6th Int. Iron and Steel Cong. 1990, ISIJ: Nagoya, Japan), pp. 598-604.

7. T. Sawai, M. Wakoh, Y. Ushima, and S. Mizoguchi, in Metallurgy of oxides in steels 3: effect of $\mathrm{Zr}$ on the precipitation of MnS in low carbon steels (Proc. 6th Int. Iron and Steel Cong. 1990, ISIJ: Nagoya, Japan), pp. 605-611.

8. S. Ogibayashi, K. Yamaguchi, M. Hirai, H. Goto, H. Yamaguchi, and K. Tanaka, in Metallurgy of oxides in steels-4: the features of oxides in Ti-deoxidized steel (Proc. 6th Int. 
Iron and Steel Cong. 1990, ISIJ: Nagoya, Japan), pp. 612617.

9. O. Wijk, in Inclusion Engineering (Proc. 7th Int. Conf. Refining Process (SCANINJECT VII), 1995, Luleå, Sweden), pp. 35-67.

10. D. Loder, S.K. Michelic, and C. Bernhard, J. Mater. Sci. Res. 6, 24 (2016).

11. H. Aaronson and C. Wells, JOM 8, 1216 (1956)

12. T. Koseki, Weld. World 49, 22 (2005).

13. D.S. Sarma, A. Karasev, and P. Jönsson, ISIJ Int. 49, 1063 (2009).

14. W. Mu, P.G. Jönsson, and K. Nakajima, High Temp. Mater. Proc. 36, 309 (2017).

15. H. Chikama, H. Shibata, T. Emi, and M. Suzuki, Mater. Trans., JIM 37, 620 (1996).

16. H. Shibata, H. Yin, and T. Emi, Philos. Trans. R. Soc. Lond. A 356, 957 (1998).

17. H. Yin, H. Shibata, T. Emi, and M. Suzuki, ISIJ Int. 37, 936 (1997).

18. H. Yin, H. Shibata, T. Emi, and M. Suzuki, ISIJ Int. 37, 946 (1997).

19. H. Shibata, H. Yin, S. Yoshinaga, T. Emi, and M. Suzuki, ISIJ Int. 38, 149 (1998).

20. K. Nakajima and S. Mizoguchi, Metall. Mater. Trans. B 32, 629 (2001).

21. W. Mu, N. Dogan, and K.S. Coley, Metall. Mater. Trans. B 48, 2379 (2017).

22. In-situ Observation at Ultra High Temperature Confocal Scanning Laser Microscope (VL2000DX-SVF17S) (2018), https://www.lasertec.co.jp/en/products/microscope/laser/vl2 000dx.html.

23. Yonekura MFG. Confocal scanning laser microscope (2018), http://yonekuramfg.wixsite.com/ht-cslm.

24. H. Shibata and T. Emi, Materia Japan 36, 809 (1997).

25. I. Sohn and R. Dippenaar, Metall. Mater. Trans. B 47, 2083 (2016).

26. W. Mu, H. Shibata, P. Hedström, P.G. Jönsson, and K. Nakajima, Steel Res. Int. 87, 10 (2016).

27. K. Fujiwara, K. Nakajima, T. Ujihara, N. Usami, G. Sazaki, H. Hasegawa, S. Mizoguchi, and K. Nakajima, J. Cryst. Growth 243, 275 (2002).

28. A. Lombardi, W. Mu, C. Ravindran, N. Dogan and M. Barati, Mater. Charact., 2018. (in press).

29. A. Lombardi, W. Mu, C. Ravindran, N. Dogan, and M. Barati, J. Alloys Compd. 747, 131 (2018).

30. T. Hanamura, H. Shibata, Y. Waseda, H. Nakajima, S. Torizuka, T. Takanashi, and K. Nagai, ISIJ Int. 39, 1188 (1999).

31. D. Phelan and R. Dippenaar, Metall. Mater. Trans. A 35, 3701 (2004).

32. D. Phelan, N. Stanford, and R. Dippenaar, Mater. Sci. Eng. A 407, 127 (2005).

33. N. Kikuchi, S. Nabeshima, Y. Kishimoto, T. Matsushita, and S. Sridhar, ISIJ Int. 47, 1255 (2007).
34. N. Kikuchi, S. Nabeshima, Y. Kishimoto, T. Matsushita, and S. Sridhar, ISIJ Int. 48, 934 (2008).

35. N. Kikuchi, S. Nabeshima, Y. Kishimoto, Y. Ishiguro, and S. Sridhar, ISIJ Int. 49, 1036 (2009).

36. N. Kikuchi, S. Nabeshima, T. Yamashita, Y. Kishimoto, S. Sridhar, and T. Nagasaka, ISIJ Int. 51, 2019 (2011).

37. T. Yamada, H. Terasaki, and Y. Komizo, Weld. Int. 23, 376 (2009).

38. D. Zhang, D.H. Terasaki, and Y. Komizo, Acta Mater. 58, 1369 (2010).

39. Y. Komizo and H. Terasaki, Sci. Technol. Weld. Joining 16, 56 (2011).

40. Y. Komizo and H. Terasaki, Sci. Technol. Weld. Joining 16, 61 (2011).

41. T. Yamada, Y. Yonemoto, S. Yamashita, T. Muramatsu, and Y. Komizo, Q. J. Jpn. Weld. Soc. 29, 86s (2011).

42. D. Zhang, Y. Shintaku, S. Suzuki, and Y. Komizo, Metall. Mater. Trans. A 43, 447 (2012).

43. A. Takada, H. Terasaki, and Y. Komizo, Sci. Technol. Weld. Joining 18, 91 (2013).

44. X.F. Zhang, Y. Komizo, T. Yokota, K. Yasuda, and K. Oi, Mater. Sci. Technol. 29, 1363 (2013).

45. M. Jiang, X. Wang, Z. Hu, K. Wang, C. Yang, and S. Li, Mater. Charact. 108, 58 (2015).

46. Z. Hu, C. Yang, M. Jiang, G. Yang, W. Wang, and X. Wang, Acta Metall. Sin. 47, 971 (2011).

47. W. Bin and S. Bo, Steel Res. Int. 83, 487 (2012).

48. X. Wan, R. Wei, L. Cheng, M. Enomoto, and Y. Adachi, J. Mater. Sci. 48, 4345 (2013).

49. X. Wan, K. Wu, G. Huang, and R. Wei, Steel Res. Int. 85, 243 (2014).

50. X. Wan, K. Wu, G. Huang, R. Wei, and L. Cheng, Int. J. Min. Metall. Mater. 21, 878 (2014).

51. W. Mu, P.G. Jönsson, and K. Nakajima, ISIJ Int. 54, 2907 (2014).

52. W. Mu, P.G. Jönsson, and K. Nakajima, J. Mater. Sci. 51, 2168 (2016).

53. W. Mu, H. Shibata, P. Hedström, P.G. Jönsson, and K. Nakajima, Metall. Mater. Trans. B 47, 2133 (2016).

54. Z. Wu, W. Zheng, G. Li, H. Matsuura, and F. Tsukihashi, Metall. Mater. Trans. B 46, 1226 (2015).

55. D. Loder and S. Michelic, Mater. Sci. Technol. 33, 162 (2017).

56. D. Loder, S.K. Michelic, A. Mayerhofer, and C. Bernhard, Metall. Mater. Trans. B 48, 1992 (2017).

57. D. Loder, S.K. Michelic, A. Mayerhofer, C. Bernhard, and R. Dippenaar, In situ observation of acicular ferrite formation using HT-LSCM: Possibilities, challenges and influencing factors (Materials Science and Technology Conference and Exhibition MS\&T (United States: Association for Iron \& Steel Technology, 2014), p. 469.

58. X. Wan, K. Wu, L. Cheng, and R. Wei, ISIJ Int. 55, 679 (2015).

59. S. Liu and D.L. Olson, Weld. J. 65, 139s (1986). 